\title{
Marcas y patentes como garantías a la inversión extranjera en Cuba. Comentarios al Decreto Ley 14/2020 "De la prenda y la hipoteca"
}

\author{
$* * * *$ \\ Lisset Castro Caballero \\ Abogada y agente oficial de marcas Bufete Internacional S.A. (Cuba) \\ lisset@bufeteinternacional.cu
}

Recibido: 7 de mayo de 2021

Aceptado: 30 de junio de 2021

Resumen

En el presente artículo se reflexiona sobre la procedencia de los derechos de propiedad intelectual como garantía de operaciones comerciales en la República de Cuba, específicamente las marcas y patentes. Se analizan, además, las regulaciones específicas para generar este tipo de garantía en Cuba, concretamente el Decreto Ley 14/2020 "De la prenda y la hipoteca".

Palabras clave: prenda, propiedad industrial, garantías, inversión extranjera, Cuba.

Trademarks and Patents as Guarantees to Foreign Investment in Cuba. Comments to Decree Law 14/2020 “On pledge and mortgage"

\footnotetext{
Abstract

The present article reflects on the origin of intellectual property rights as commercial guarantees in the Republic of Cuba, specifically trademarks and patents. It also analyzes the specific regulations to generate this type of guarantee in Cuba, specifically the Decree Law 14/2020 "On pledge and mortgage".
} 
Key words: pledge, industrial property, guarantees, foreign investment, Cuba.

\section{Marcas e patentes como garantias para o investimento estran- geiro em Cuba. Comentários ao Decreto-Lei 14/2020 “Sobre penhor e hipoteca"}

\section{Resumo}

Este artigo reflecte sobre a origem dos direitos de propriedade intelectual como garantia para as transacçóes comerciais na República de Cuba, especificamente marcas registadas e patentes. Analisa também os regulamentos específicos para gerar este tipo de garantia em Cuba, especificamente o Decreto-Lei 14/2020 "Sobre penhor e hipoteca".

Palavras-chave: promessa, propriedade industrial, garantias, investimento estrangeiro, Cuba.

\section{Introducción}

La inversión extranjera, a pesar de no ser un fenómeno novedoso, ha aumentado su impacto en las economías mundiales en los últimos decenios, pudiéndose apreciar un crecimiento importante en el monto de los recursos financieros internacionales que buscan adquirir una cierta participación en empresas localizadas en lugares distintos al de su país de origen. ${ }^{1}$

La inversión extranjera directa (IED), entendida como una inyección de capital a largo plazo por un agente comercial en un país del cual no es residente, puede tomar diversas formas: desde el inicio de operaciones de una empresa hasta la adquisición de activos. (Campos, Gutiérrez y Saracho Martínez, s.f., p. 29).

Como se señala y se concluye en el estudio realizado por Campos, Gutiérrez y Saracho Martínez (s.f., pp. 31-32), en los últimos años se puede notar a nivel mundial una mayor atención y atracción para la inversión extranjera con mayor valor agregado, como puede ser el caso de los derechos de propiedad intelectual (PI).

1 Quizá, en el año 2020 y en lo que va de 2021 se pueda hablar de un decrecimiento de estas modalidades y de una contracción económica mundial debido al impacto negativo de la pandemia de COVID-19 en todas las economías. 
A nivel mundial se puede apreciar una tendencia a notar una fuerte presencia de los derechos de propiedad intelectual, y más específicamente de propiedad industrial en las inversiones extranjeras.

En igual orden, precisa Longcrof (2008): "De modo paralelo la financiación de la PI basado en activos de propiedad intelectual para acceder al crédito, está suscitando cada vez mayor interés en el mundo de la propiedad intelectual" (párr. 1).

De acuerdo con Guadagno y Wunsch-Vincent (2020, p. 72), ${ }^{2}$ la afirmación anterior tiene base en el impacto económico de los derechos de propiedad intelectual como activos valiosos y también como fuentes de financiación, especialmente en los últimos años. Las empresas intentan obtener financiación y precisamente los intangibles son una fuente trascendente (Longcrof, 2008, párr. 24).

Por otra parte, tal y como seńala la citada autora:

Desde una perspectiva jurídica, cabe señalar que la mayoría de los ordenamientos todavía no prevén instrumentos jurídicos adecuados con relación a la financiación a través de los activos intangibles, incluida la propiedad intelectual [...], la cuestión de la financiación basada en la propiedad intelectual constituye actualmente el objeto de formulación de políticas a nivel internacional. (Longcrof, 2008, párr. 24)

Como nota al margen, y de acuerdo con datos oficiales de Guadagno y Wunsch-Vincent (2020), cabe señalar que:

América Latina y el Caribe sigue siendo una región con grandes desequilibrios. La región se caracteriza en general por sus bajas inversiones en $\mathrm{I}+\mathrm{D}$ e innovación, su incipiente uso de los sistemas de propiedad intelectual y la desconexión entre los sectores público y privado en la priorización de la I+D e innovación. [...] Además,

2 En cita de las mentadas autoras: "La propiedad intelectual se ha utilizado durante mucho tiempo para señalar la calidad y la viabilidad de un proyecto de innovación. Esto ha resultado útil para reducir los costes de financiación, atraer a nuevos inversores, optar a programas gubernamentales y entrar en consorcios internacionales. La PI también constituye una especie de 'póliza de seguro': si la empresa quiebra, sus ideas y activos intangibles pueden seguir vendiéndose o licenciándose" (Guadagno y Wunsch-Vincent, 2020, p. 72). 
la mayoría de las inversiones en I+D son principalmente públicas, con una baja proporción de financiación del sector privado. En general, los sectores económicos de la región no son intensivos en tecnología y el crecimiento de la productividad laboral se mantiene en niveles bajos. (p. 74)

La República de Cuba no ha estado ajena a estas tendencias y, desde hace varios ańos, ha delineado políticas encaminadas a promover la captación de capital foráneo y, con ello, la inversión extranjera en el país como una de las importantes apuestas para alcanzar un mayor desarrollo económico y social, tanto a niveles macro como micro.

De la mano de las políticas gubernamentales para crear un escenario favorable para estas inversiones foráneas en el país, surgen diversas normas jurídicas que se han ido promulgando en la República de Cuba a tono con toda una reestructuración económica y legal que desde hace varios años se lleva a cabo en el país.

A nivel doméstico, el desarrollo de la inversión extranjera ha ido tomando auge, especialmente a partir de la promulgación de la Ley 118 de 2014 "Ley de la Inversión Extranjera". De forma general, esta inversión se ha centrado en las variantes tradicionales en su formación y garantías para el inversor. ${ }^{3}$

En los últimos años se ha podido apreciar que algunos de los proyectos creados como inversión extranjera en Cuba tienen una fuerte base en los derechos de propiedad intelectual, debido a que se han creado empresas mixtas (conformadas por capital cubano y extranjero) en licencias de patentes y también de marcas. ${ }^{4}$

Con tales antecedentes, es posible decir que ya existe un inicio de camino, aunque todavía incipiente, en formas de inversión extranjera con sustentos en fuentes menos tradicionales. Con este propósito, se pretende fortalecer el aún debilitado sistema de propiedad intelectual en Cuba, logrando el llamado "ciclo completo de I+D". Para lograr tales objetivos, es necesario contar con las fuentes de fi-

3 Lo aseverado no se sustenta en datos oficiales, sino en la experiencia práctica de la autora.

4 Hasta la fecha, no es de conocimiento de la autora formas de inversión extranjera sustentada en modalidades de derecho de autor. 
nanciación suficientes y generalmente altas, para lo que se necesita, casi inexorablemente, captar capital foráneo. ${ }^{5}$

\section{Desarrollo}

\subsection{Los derechos de propiedad industrial como garantías a la inversión extranjera}

Los bienes intangibles como los referidos a los de propiedad intelectual, y más específicamente las marcas y las patentes, pueden, además de servir como fuente de financiamiento, ser explotadas como garantías de relaciones comerciales, lo que puede implicar el aumento de la cuantía del crédito disponible. El razonamiento de Longcroft (2008) explica claramente la situación de los intangibles en el sector financiero:

[...] en los casos en que los prestatarios ofrecen garantías a través de sus derechos sobre patentes, marcas u obras protegidas por derecho de autor, el fondo de garantía incrementa su valor y aumentan las posibilidades de obtener un préstamo. Algunos bancos también utilizan los activos de propiedad intelectual como factor para mejorar las condiciones del crédito. El número de este tipo de operaciones basadas en la propiedad intelectual está aumentando, y el creciente flujo de fondos ligados a la concesión de licencias sobre derechos de propiedad intelectual está atrayendo la atención de Wall Street $\mathrm{y}$ de los mercados financieros de todo el mundo. Los acuerdos de transformación de activos intangibles en valores (titularización o bursatilización) permiten a los titulares de derechos de propiedad intelectual pedir dinero prestado más fácilmente y de forma más segura a entidades crediticias con las suficientes garantías. (párr. 6)

El criterio anterior es seguido a nivel internacional en cuanto a la

5 Cuba cuenta con un fuerte potencial en el campo de las investigaciones científicas y, en consecuencia, de obtención de patentes. De hecho, lo ha demostrado en la crisis generada por la COVID-19, contando con cuatro candidatos vacunales. A pesar de lo anterior, llama la atención que no se encuentra referencia de la incidencia de la PI en el sector económico en el Global Innovation Index 2020 (Guadagno y Wunsch-Vincent, 2020). 
utilización de la propiedad industrial como garantía en préstamos y como herramienta para generar dinero de forma directa. ${ }^{6}$

Con este telón de fondo, es innegable la visibilidad de los derechos de propiedad intelectual como fuente de financiación y como cebo para atraer a inversores; a la vez, pueden fungir tales derechos también como garantías, en sentido estricto y técnico, de los propios proyectos de inversiones o de otros.

En el caso de Cuba, si bien puede ser catalogada todavía como muy incipiente la utilización directa de derechos de propiedad intelectual como activos y/o aportaciones de las inversiones extranjeras en Cuba, se puede aseverar, sin temor a equivocarse, que no existe práctica ni implementación de tales derechos en el país.

Precisamente con conocimiento de las potencialidades de esta modalidad de explotación de los derechos de propiedad intelectual (de los derechos e intangibles en general) y con la idea de fomentar sus usos, se promulgó en Cuba el 23 de octubre de 2020 el Decreto Ley 14 "De la prenda y la hipoteca", a los efectos de actualizar según los contextos modernos las regulaciones referidas a las garantías de obligaciones, específicamente la prenda y la hipoteca.

Con tales antecedentes, partiendo de la posibilidad de establecer como garantías a la inversión extranjera derechos sobre PI, nos proponemos realizar un breve análisis de dicha norma y su implicación para la inversión extranjera en Cuba, específicamente para las modalidades de marcas y patentes. ${ }^{7}$

\subsection{Análisis y referencia al Decreto Ley $14 / 2020$}

\subsubsection{Generalidades}

El Decreto Ley 14 "De la prenda y la hipoteca", de 24 de septiembre de 2020, aunque publicada en la Gaceta Oficial el 23 de octubre de ese año, tiene como objetivo expreso el de propiciar la utilización de

6 Para ampliar información, ver Guadagno y Wunsch-Vincent (2020).

7 En este acercamiento a la norma de referencia y al objeto del artículo, la autora se centrará en esas dos modalidades de derechos de propiedad industrial. El estudio y aplicación de otras variantes de propiedad intelectual en sentido amplio como garantías forman parte de un proyecto más ambicioso y no de estas consideraciones iniciales. 
la prenda por las personas naturales y jurídicas en el ámbito de sus relaciones económicas y extenderla a los derechos, así como posibilitar la prenda de acciones.

Llama la atención la brevedad de dicha disposición jurídica, la que se limita a modificar determinados artículos del Código Civil, del Decreto Ley del Registro Mercantil y de la Ley de Procedimiento Civil, Administrativa, Laboral y de lo Económico en lo referente a la regulación de la prenda y la hipoteca, la inscripción de acciones en el referido mercantil y cuestiones adjetivas, sin precisar detalles novedosos para su implementación, especialmente en lo relativo a los bienes intangibles.

En relación con la posibilidad de prendar derechos y, con ellos, entenderse incluidos los derechos de propiedad industrial objeto de las presentes reflexiones, queda al descubierto un diapasón de cuestiones que no parecen tener respuesta en este cuerpo legal, al menos no para esta autora, máxime cuando tampoco hay referencia a la aplicación de normas especiales que rigen estas modalidades.

Para los que no son conocedores de la materia económica doméstica cubana, no puede perderse de vista que los actores económicos pueden dividirse en el sector empresarial, ya sea estatal, de sociedades civiles mercantiles y de inversión extranjera y el sector de gestión no estatal, el cual se refiere esencialmente a los llamados "trabajadores por cuenta propia”, conocidos como TCP (aquellas personas naturales que no tienen una categoría empresarial y que necesitan obtener licencias para ejercer las actividades que estén autorizadas), y las cooperativas, distinguibles en agropecuarias y no agropecuarias.

Pasemos entonces al análisis de las cuestiones principales de la prenda en lo aplicable a los derechos intelectuales, específicamente a las marcas y patentes.

\subsubsection{Exégesis normativa}

a) En el primer artículo del Decreto Ley 14 de 2020 se dispone la modificación de los artículos 270 al 277 y el 288 de la Ley 59 "Código Civil”, de 16 de julio de 1987, y su redacción actual. ${ }^{8}$

8 Decreto Ley 14/2020, artículo 1: "Modificar los artículos desde el 270 al 


\section{No puede perderse de vista que esta regulación aplicable tanto al}

277 y el 288 de la Ley No. 59 'Código Civil', de 16 de julio de 1987, los que quedan redactados de la manera siguiente: 'Artículo 270.1. El derecho de prenda faculta al acreedor a satisfacer su crédito, preferentemente a cualquier otro acreedor, con cargo al valor del bien mueble o derecho prendado del deudor. 2. Puede constituirse prenda con desposesión o sin desposesión del bien o derecho. 3. La garantía de la prenda se extiende a los gastos, los intereses y la indemnización o sanción pecuniaria. 4. La constitución de la prenda requiere siempre la forma escrita y no puede ser oponible a terceros, si no consta en instrumento público o privado de fecha cierta, cualquiera que sea el valor del crédito. 5. Si el bien o derecho prendado genera frutos o intereses, el acreedor debe percibirlos e imputarlos al pago de la deuda, primero a gastos e intereses y, posteriormente, al capital; es válido el pacto en contrario. Artículo 271. La prenda, además, puede constituirse sobre bienes y derechos propiedad de un tercero si este lo consiente. Artículo 272. Los bienes y derechos inembargables no pueden ser objeto de prenda. Artículo 273. En el documento constitutivo de la prenda se debe consignar: a) El nombre y domicilio de las partes y, en su caso, del tercero dueño del bien o derecho pignorado; b) la descripción de dicho bien o derecho; c) la estimación de su valor, expresada en dinero; d) el lugar donde se encuentra; e) la obligación garantizada con la prenda; y f) el término de su vencimiento. Artículo 274.1. $\mathrm{El}$ acreedor no puede usar los bienes y derechos que recibió en prenda y está obligado a conservarlos en forma adecuada y a responder por su pérdida o deterioro frente al deudor, si no prueba que ocurrió por culpa de este. 2 . Si se trata de prenda sin desposesión, el deudor puede usar los bienes y derechos según su destino o cambiarlos de lugar con el consentimiento del acreedor. 3 . El incumplimiento a que se contraen los apartados anteriores da derecho al deudor a: a) Dar por extinguida la garantía y exigir que el bien o derecho le sea restituido; b) pedir que el bien se ponga en depósito a costa del acreedor; y c) reclamar dańos y perjuicios. Artículo 275.1. El acreedor a quien no se le haya pagado su crédito puede enajenar el bien o derecho en subasta pública. 2. Si en la subasta no se presenta comprador, o el precio ofrecido no cubre el valor del bien o derecho dado en prenda, este se adjudica al acreedor, quien está obligado a dar al deudor un recibo del pago de la totalidad del crédito. 3. Enajenado el bien o derecho, se entrega al deudor el producto de la venta, descontándole el importe de su deuda y el de los gastos causados. Artículo 276.1. El derecho de prenda se hace efectivo mediante la venta de los bienes o derechos, por el valor que tengan en ese momento, por cualquiera de las vías legales. 2. Efectuada la venta, el acreedor debe rendir cuenta al deudor, quien puede impugnarla, sin que ello afecte la validez de la enajenación. Artículo 277. En la obligación garantizada con prenda el acreedor solo puede satisfacer su crédito con el bien o derecho gravado". 
sector de personas naturales como jurídicas se supedita al ámbito de las relaciones comerciales.

b) Como novedoso se regula la posibilidad de convenir un derecho de prenda con cargo a derechos y a acciones y no únicamente al valor del bien mueble del deudor o de un tercero.

Nótese que el modificado artículo del Código Civil preveía únicamente la prenda sobre bienes muebles. ${ }^{9}$ De ahí que se puede entender como un avance la posibilidad de prendar derechos y los llamados "bienes inmateriales de propiedad intelectual", entre los que podemos mencionar los derechos sobre patentes, marcas y derechos de autor, entre otros.

Para analizar la procedencia del derecho de prenda sobre tales modalidades de propiedad industrial, se considera prudente referirse a su naturaleza y forma de constitución. ${ }^{10}$

Cabe acotar que en cuanto el derecho de autor, el registro no es constitutivo de derechos, sino más bien un medio probatorio con carácter iuris tantum, pues los derechos se adquieren ad initium con la creación de la obra.

Por su parte, de acuerdo con las normas nacionales, no es obligatorio que una marca se inscriba en el Registro de la Oficina Cubana de la Propiedad Industrial (en adelante, OCPI), salvo excepciones, como es el caso de los rótulos de establecimiento en locales de trabajadores por cuenta propia. ${ }^{11}$ No obstante, debe tenerse en cuenta

$9 \quad$ Ley 59/1987, artículo 270.1: "El derecho de prenda faculta al acreedor a satisfacer su crédito preferentemente a cualquier otro acreedor, con cargo al valor de un bien mueble recibido del deudor".

10 A los efectos de no extender los presentes comentarios y dada su naturaleza, se ha entendido que no es necesario hacer referencia a las definiciones de "marca" y "patente".

11 La Resolución 31, de 2 de julio de 2018, del presidente del Instituto de Planificación Física dispone el procedimiento que regula el otorgamiento de la autorización que se les expide a los trabajadores por cuenta propia para el contenido y la colocación de carteles por las Direcciones Municipales de Planificación Física. La esencia jurídica de dicha norma es regular los requerimientos para la colocación de los carteles en el ejercicio del trabajo por cuenta propia. Entre tales exigencias, esencialmente de índole administrativa, se destaca la obligatoriedad de registro, por parte del promovente (trabajador por cuenta propia), de aquellos signos distintivos a utilizarse en 
que en cuanto a los derechos, y salvo las excepciones previstas en la norma, es a partir de la inscripción correspondiente que se obtienen los derechos bajo el axioma, también aplicable en nuestro régimen jurídico de "primero en tiempo, primero en derecho". ${ }^{12}$

Por otra parte, para el otorgamiento de licencias marcarias, tal y como se prevé en el artículo 83.1 del Decreto Ley 203 de 1999, es mandatorio contar con el registro de marcas. ${ }^{13}$

En el campo de las patentes, es a partir de la inscripción en el referido Registro que se obtiene la patente y, con ella, sus plenos derechos. ${ }^{14}$ En el caso de Cuba, similar a la posición internacional mayoritaria, el proceso de obtención de la patente es dilatado en el tiempo y, de hecho, en muchas ocasiones se pagan las anualidades correspondientes sin tener todavía el derecho confirmado. De ahí que, a diferencia del sistema marcario, se permite en estos casos de patentes, conceder licencias voluntarias sobre tales derechos todavía en estado de solicitud.

En este orden, cabe entonces preguntarse si es posible otorgar derechos pignoraticios en ese tipo de bienes inmateriales si no se cuenta con su correspondiente registro.

un cartel ante la OCPI. La resolución de referencia responde a la intención de perfeccionar, corregir deficiencias, ordenar y controlar la actividad y el ejercicio de esta forma de empleo, por lo que, según datos oficiales, involucraría a 593664 personas, lo que representa el 13 por ciento de la ocupación del país y el 5 por ciento de los ingresos tributarios. Llama la atención que el requisito de obligatoriedad de registro de signos distintivos para el uso de los carteles quede ceñido para este sector de trabajo, no siendo así para empresas, cooperativas y otras entidades que también hagan uso de carteles contentivos de signos distintivos. La norma legal de referencia no especifica qué tipo de signos se debe registrar. Se podría colegir de la naturaleza de su obligación que se hace referencia a los rótulos de establecimientos, en tanto son aquellos destinados a identificar a un establecimiento o local determinado. No se continúa desarrollando este punto por no ser objetivo del presente documento.

12 Decreto Ley 203/1999, artículo 40: "El registro de la marca confiere a su titular el derecho exclusivo de usarla en el tráfico económico".

13 Decreto Ley 203/1999, artículo 83.1: "El titular del registro de una marca puede autorizar su uso a terceros a través de licencias. Las licencias serán 110 exclusivas, salvo pacto en contrario".

14 Decreto Ley 290/2011, artículo 2: "Los derechos que se obtienen en virtud de este Decreto Ley se otorgan a través de patentes [...]". 
Tales diferencias entre marcas y patentes, al parecer, no encuentran reflejo en el ámbito de la prenda en la norma de referencia. Si nos remitimos a la norma específica, concretamente el Decreto Ley 203/1999 y su Reglamento, no podemos encontrar respuesta, pues nada se prevé sobre tal particular, en tanto no es objeto de dichos cuerpos legales lo concerniente a derechos de prenda, dada las fechas de promulgación de estas. Tampoco se encuentra referencia a estos particulares en regulaciones sobre patentes de reciente promulgación, como es el Reglamento del Decreto Ley 290 "De las Invenciones y Dibujos y Modelos Industriales" o el Decreto 342/2018.

En opinión de esta autora, siguiendo la hermenéutica legal, es aplicable por analogía igual línea que la prevista para las licencias y la constitución de las prendas sobre este tipo de bienes, o sea, en el caso de las marcas, debe tenerse el derecho otorgado, y en el de las patentes, podría otorgarse derecho de prenda aun en estado de solicitud.

c) En otro apartado del mismo artículo se mantiene la posibilidad de conveniar la prenda con o sin desposesión. Esta regulación tiene un sustento en la tradicional composición de la prenda sobre bienes muebles. En el caso de los bienes inmateriales, esta regulación podría tener un análisis particular. En el caso de una prenda con desposesión, podría entenderse similar a tener los derechos de licencia o podría hablarse de una cesión "temporal" de titularidad, cuestión no prevista en nuestras normas nacionales. ¿Permitiría esta desposesión la explotación durante la prenda de este tipo de intangibles sustentado en dicha prenda? La respuesta, a priori, debe ser que no.

En caso de constituirse bajo esta modalidad, con la consabida imposibilidad de una "posesión" en sentido lato sobre dichos bienes, no debe entenderse extendida a la posibilidad de explotación de los derechos intelectuales sobre cualquier modalidad de derecho de propiedad industrial, salvo pacto en contrario. En ese supuesto, según criterio de la autora, no sería suficiente la regulación en el derecho de prenda, sino que debe ajustarse a los requerimientos exigidos para este tipo de actos, como es el caso de las licencias.

d) La garantía de la prenda se extiende a los gastos, los intereses y la indemnización o sanción pecuniaria.

Este es un elemento que también se mantiene y que conlleva una previsión en la inclusión del derecho de prenda, relacionado con el 
avalúo del bien y la adecuada conformación de una garantía que permita reducir los riesgos ante un incumplimiento de las obligaciones.

Así, es necesario tener la "certeza" de que el intangible prendado es suficiente para cubrir todos estos elementos. Claro está, para el caso de los intangibles, al menos a nivel internacional, los valores de estos varían mucho según el mercado.

e) La constitución de la prenda requiere siempre la forma escrita y no puede ser oponible a terceros si no consta en instrumento público o privado de fecha cierta, cualquiera sea el valor del crédito.

Este es un requisito exigido en la mayoría de las legislaciones que regulan esta garantía pignoraticia. De su lectura se desprende que esta exigencia de escritura parece tener un carácter ad probationem en relación con su eficacia frente a terceros y no ad solemnitatem.

Así, de no existir un documento escrito y firmado, seguiría existiendo un pacto vinculante entre las partes, pero faltaría la eficacia frente a terceros, lo que también podría frustrar el verdadero sentido de este tipo de garantías sobre cualquier bien y notablemente sobre los inmateriales. Cabe destacar que uno de los efectos de la prenda no es solo de la obvia garantía y satisfacción de créditos y obligaciones, sino también de publicidad a terceros, de preferencia entre acreedores, así como de minimización de riesgos. De ahí que, a pesar de lo referido en el párrafo anterior, es altamente justificable tal exigencia.

Por otra parte, llama la atención que no se haya previsto inscripción registral para tales efectos, especialmente en lo relativo a los derechos de propiedad industrial. No se puede perder de vista que es precisamente la inscripción en las Oficinas Nacionales una exigencia para que determinados actos, generalmente dispositivos, tengan efecto frente a terceros $y$, en consecuencia, que el acto tenga plena efectividad frente a ellos.

En la norma no se encuentra referencia a la obligación de registro de los derechos de prenda sobre los derechos e intangibles.

El artículo 2 que modifica el inciso e) del artículo 20.2 del Decreto Ley 226 “Del Registro Mercantil”, de 6 de diciembre de 2001, queda redactado de la siguiente manera: 
e) las emisiones de acciones, expresando la serie y número de los títulos de cada emisión, su interés, rédito, amortización y prima; y cuando así lo requieran, la cantidad total de la emisión y los bienes, obras, derechos y obligaciones que se afecten a su pago, incluida la constitución de prenda de acciones autorizadas.

Tal regulación no es de aplicación a los bienes objeto de análisis, por lo que se colige que solo es exigible la inscripción de la prenda en el caso de las acciones y no así para las otras modalidades.

En el caso de las prendas que se puedan generar sobre derechos de propiedad industrial, sería muy saludable instituir la obligación de su inscripción en el registro, lo que dotaría al acto de mayor seguridad jurídica e impediría cualquier acto dispositivo sobre dichos bienes.

La exigencia de un sistema de registro para este tipo de garantías dota de transparencia al sistema crediticio y otorga más confianza. En criterio de Longcroft (2008),

Un sistema de registro general de créditos (como el previsto en la Guía Legislativa de la CNUDMI sobre las operaciones garantizadas) ofrecerá certidumbre jurídica a las entidades crediticias al aportar transparencia sobre la estructura crediticia del deudor y dará notoriedad a las operaciones garantizadas. (párr. 26)

A la vez, la exigencia -o al menos la posibilidad- de registro tendría un impacto directo en su valuación y en su posible incidencia o utilización en cualquier proyecto de inversión extranjera.

Así, las licencias y cesiones de marcas y/o patentes y el resto de las modalidades de PI deben ser inscriptas en la OCPI para que tenga eficacia el acto y pueda ser oponible frente a terceros. ${ }^{15}$

En todo caso, lo anterior conllevaría otra modificación legislativa, pues de acuerdo con la regulación taxativa del Decreto Ley 203 y su Reglamento no parece haber cabida para este tipo de inscripciones, ni la propia OCPI es dable a actuaciones que no sean expresas.

15 Decreto Ley 203/1999, artículo 84: "Los contratos de licencia deben ser anotados en la Oficina, y solo surtirán efectos frente a terceros a partir de la fecha de la anotación”. 
f) Artículo 271. La prenda, además, puede constituirse sobre bienes y derechos propiedad de un tercero si este lo consiente.

Esta posibilidad se preveía desde su regulación primaria en el Código Civil y, para el caso que nos ocupa, la prenda sobre derechos de PI aplicaría el resto de las consideraciones comentadas previamente.

Sería cuestionable la utilidad de prendar un intangible de un tercero de cara a la real coadyuvación del cumplimiento de las obligaciones, así como frente a las autorizaciones gubernamentales que para algunos casos se prevén en la constitución de dicha garantía.

g) Artículo 272. Los bienes y derechos inembargables no pueden ser objeto de prenda.

También se mantiene como parte de la legislación actual, a tono con los principios básicos refrendados desde la carta magna de la República de Cuba.

Nótese que, de forma general, en la Constitución de la República de Cuba se regula en sus preceptos 23 y 24 como reflejo de los principios básicos de la propiedad socialista de todo el pueblo la inalienabilidad, imprescriptibilidad e inembargabilidad de dichos bienes.

La Ley 7/1977 "Ley de Procedimiento Civil, Administrativo, Laboral y Económico", de 19 de agosto de 1977 (en adelante, LPCALE), modificada por el Decreto Ley 241/2006, de 26 de septiembre de 2006, regula de una forma más amplia, en su artículo 463, el catálogo de bienes y derechos considerados inembargables. Dicho enunciado normativo reza:

ARTÍCULO 463.- Podrán ser objeto de embargo, medida cautelar o asegurativa, toda clase de bienes y derechos, con excepción de los que a continuación se expresan:

1) los bienes del patrimonio estatal administrados directamente por el Estado y los administrados por empresas y entidades estatales, con excepción de los recursos financieros de éstas y los que así se autorice en la legislación especial;

2) el inmueble que constituya la vivienda permanente del deudor;

3) los bienes de propiedad personal destinados al uso imprescindible del deudor;

4) los medios o instrumentos de trabajo de uso necesario para el ejercicio de la profesión, arte u oficio; 
5) los vehículos que constituyan instrumentos o medio de trabajo personal;

6) las pensiones alimenticias;

7) las tierras integrantes del mínimo vital y el área de autoconsumo del pequeño agricultor y los demás bienes inherentes a ella, incluyendo los aperos de labranza, los animales y crías de éstos.

Serán inembargables los dos tercios de los sueldos, salarios y prestaciones de seguridad social, pero en los casos de reclamaciones de pensiones alimenticias y créditos en favor del Estado y las empresas estatales la inembargabilidad se podrá reducir a la mitad del monto de dichos ingresos.

En ese sentido, de manera general se puede concluir que los bienes intangibles no se encuentran dentro de la lista anteriormente mencionada y pueden ser embargados y, consecuentemente, también prendados. Como excepción podrían estar aquellos intangibles que puedan ser titularidad estatal, como sería el caso de las denominaciones de origen.

h) Artículo 273. En el documento constitutivo de la prenda se debe consignar:

* El nombre y domicilio de las partes y, en su caso, del tercero dueño del bien o derecho pignorado.

Esta es una exigencia básica de identificación de las partes en cualquier acto de comercio y en la que debe existir una coincidencia con los datos que deben constar en la OCPI (referida al titular de los derechos de propiedad industrial y demás datos identificativos).

* La descripción de dicho bien o derecho.

En este caso, deben hacerse constar los datos de identificación básicos del registro de una marca y/o del registro o solicitud de la patente, a saber: número de registro y/o solicitud, denominación, fecha de entrada y/o registro, clases y/o clasificación y titular.

* La estimación de su valor, expresada en dinero.

La valuación económica de este tipo de los intangibles es precisamente una de las principales dificultades o particularidades, si se quiere, en tanto difiere de la valuación tradicional que se realiza a los bienes tangibles. Tampoco existe una metodología uniforme a nivel global para realizar una valuación (Longcroft, 2008, párr. 19). A 
pesar de lo anterior, deviene en una herramienta indispensable para otorgar financiamientos y también para concertar garantías.

Sobre los métodos de valuación, se encuentra mucha referencia al tema y diversos sistemas que se siguen a nivel internacional. A modo de ejemplo, señalamos que los métodos de valuación pueden ser el valor de la empresa, el goodwill, el valor del equipo directivo y el valor de reposición, entre otros. ${ }^{16}$

Esta diversidad de opciones y falta de unificación en cuanto a la valuación de bienes de propiedad industrial, así como las diferencias entre estos bienes y aquellos comunes, ha creado asimetrías en la información sobre la propiedad industrial y, con ello, en su aplicación específica en las inversiones.

En el caso de Cuba, coincidimos con el criterio de las reconocidas voces nacionales de Moreno Cruz y Vázquez D’Alvaré (2017), quienes aseveran que:

La determinación del valor de los derechos sobre bienes de propiedad industrial es un proceso complejo toda vez que depende de la naturaleza del derecho, alcance y fortaleza de las reivindicaciones en el caso de una patente, la cobertura territorial, su duración, la explotación previa a las licencias concedidas, los derechos vigentes en mercados de interés, así como la situación económica del sector de la economía al que se circunscriban. (párr. 12)

Para esto, en el caso de Cuba, debe contratarse a una entidad valuadora para poder determinar precisamente dicho valor $\mathrm{y}$, a la vez, poder otorgarse la garantía, cuestión que genera un costo adicional.

Como nota característica debe reseñarse que con la aprobación de la Ley 77 "Ley de la Inversión Extranjera", de 5 de septiembre de 1995, la actividad de valuación empieza a adquirir mayor relevancia en Cuba, al exigirse en dicha norma, similar a la actual Ley 118, la valuación de activos.

Actualmente, se encuentran con autorización legal y formal para

16 Existen numerosos artículos y libros referidos a la valuación de la propiedad industrial. Para mejor referencia, consultar la bibliografía, como Moreno Ávila y Patińo Gutiérrez (2020), entre otros. 
brindar este servicio mediante autorización emitida por el Ministerio de Finanzas y Precios (MFP) ${ }^{17}$ las siguientes entidades:

- Agencia Internacional de Inspección, Ajuste de Averías y Otros Servicios Conexos (INTERMAR).

- Consultores Asociados S.A. (CONAS).

- Centro Internacional de La Habana (CIH).

- Consultoría Económica (CANEC).

- Bufete Internacional.

- Banco de Crédito y Comercio (BANDEC).

- Agencia de Supervisión y Servicios Aduanales del Grupo Empresarial CIMEX (ADESA).

Lo anterior implica que la actividad de valuación ha de hacerse forzosamente a través de peritos valuadores que estén asociados a las entidades antes mencionadas. Por lo demás, las atipicidades y particularidades de los intangibles, unidas a la poca experiencia práctica en esas valuaciones, pueden dificultar, encarecer y/o entorpecer el referido proceso.

Si bien es necesario cumplir con dicha exigencia, lo anterior puede constituir un fuerte obstáculo para llevar a vías de hecho para este tipo de bienes inmateriales y mucho debe ganarse en la experiencia y valuación de activos intangibles en Cuba.

* El lugar donde se encuentra.

Este particular, precisamente por la naturaleza de los bienes intangibles, no tendría aplicación específica.

Sí debe ser necesario conocer sus datos principales y si estos se encuentran sometidos a algún tipo de limitación o de gravamen. Una vez más, se acredita la importancia de un registro de prenda para la PI.

* La obligación garantizada con la prenda.

También una exigencia básica e intrínseca a todas las garantías que siempre tienen una naturaleza accesoria al contrato u obligación principal.

* El término de su vencimiento.

Este ítem tiene una transcendencia en todas las variantes de propiedad industrial. Como naturaleza de este tipo de bienes inmateria-

17 Ver el sitio web del Ministerio de Finanzas y Precios de la República de Cuba: https://www.mfp.gob.cu. 
les es su esencia temporal. En el caso de las marcas, puede tener una vocación de perpetuidad en tanto pueden ser renovados indefinidamente como mecanismo de identificación empresarial de los bienes y/o servicios que identifica en el mercado. En el caso de nuestra norma, similar a otras legislaciones occidentales, puede ser renovado cada 10 ańos desde su fecha de solicitud. Igual sucedería con el resto de las modalidades relativas a los signos distintivos.

En todo caso, como dicha renovación es potestativa del titular, no debe preverse una extensión mayor que la del período de vigencia que reste, so pena de que caduquen sus derechos

De modo contrario, para el caso de las patentes, sí tienen un alcance temporal definido de 20 ańos desde su solicitud, por lo que una vez cumplido dicho plazo, pasan a dominio público las reivindicaciones y descripción de la patente. ${ }^{18}$

Este es un elemento muy importante a tener en cuenta al momento de otorgar una patente en concepto de prenda, pues obviamente no tendría el mismo valor o eficacia como garantía una patente próxima a caer en dominio público que otra cuyo plazo de exclusividad sea más extendido en el tiempo. Tal particular debería ser tenido en cuenta, en todo caso, al momento de la valuación del intangible.

i) Artículo 275.1. El acreedor a quien no se le haya pagado su crédito puede enajenar el bien o derecho en subasta pública.

Esta es una práctica existente desde las prendas tradicionales. En el campo de los derechos intelectuales, tienen una vasta experiencia en cuanto a subastas se refiere. Particularmente, los derechos de autor tienen una posición más adelantada por su explotación común en diversas manifestaciones artísticas, aunque existen casas de subastas especializadas en esta materia (Longcrof, 2008, párrs. 5 y 13). ${ }^{19}$

El tratamiento dado se asemeja a lo establecido en las normas adjeti-

18 No existe en Cuba, a diferencia de otros ordenamientos -como el de Estados Unidos-, la posibilidad de extender el término de protección de las patentes, como sucede con patentes de medicamentos.

19 Empresas como Ocean Tomo, IP Bewertungs AG y IP AuctionsInc celebran subastas de propiedad intelectual. Además, existen mercados de propiedad intelectual en internet, como el mercado de tecnología regentado por Yet2.com o la bolsa de tecnología dirigida por Tynax, y Pluritas, iPotential e IP Value y aglutinadores institucionales de patentes, como la empresa Intellectual Ventures. 
vas sobre las vías de apremio para ejecutar los créditos correspondientes. Hay antecedentes prácticos sobre la vía de apremio sobre bienes muebles e inmuebles esencialmente asociados con procesos económicos, o sea, aquellos que se dan en el marco de las relaciones comerciales.

Para Cuba, al menos que conozca esta autora, no existe experiencia de subastas de derechos de propiedad industrial, por lo que sería todo un reto a implementar de darse en algún momento un caso práctico.

j) Si en la subasta no se presenta comprador o el precio ofrecido no cubre el valor del bien o derecho dado en prenda, este se le adjudica al acreedor, quien está obligado a darle al deudor un recibo del pago de la totalidad del crédito.

En este supuesto de adjudicación, debe remitirse a la norma especial que implica el cambio de titularidad con su consabida anotación en el registro correspondiente.

Ahora bien, ¿podría darse el caso de que la OCPI deniegue tal registro por entender que se tipifica alguna prohibición? En el caso de que al realizarse la anotación de cambio de titular se tipifique alguna de las prohibiciones absolutas o relativas del derecho de marca, como pueden ser los derechos anteriores de terceros o posible riesgo de confusión o error en el consumidor, podría entonces no accederse a la inscripción de tal acto.

Otro supuesto podría darse ante una garantía no sobre toda la marca, sino sobre algunas de sus clases; surge así el interrogante de si, luego de la actuación judicial -entiéndase, subasta-, podrían coexistir distintos titulares sobre igual marca, pero de clases diferentes.

Quien sigue el sistema de registro de marcas ante la OCPI conocerá que esta suele ser muy rigurosa en cuanto a la interpretación de prohibiciones y coexistencia se refiere.

Ante estos casos hipotéticos, pero no bizantinos, cabe preguntarse qué solución legal podría darse. Lo anterior merecería ser objeto de un análisis posterior, aunque a priori opinaría que podría denegarse el registro si en su análisis el examinador entiende que se tipifica alguna prohibición.

En todo caso, debería ser reglado en alguna norma específica o al menos en el documento privado, el que en todo caso nunca podría contradecir una norma imperativa o prohibitiva. 
k) Artículo 277. En la obligación garantizada con prenda, el acreedor solo puede satisfacer su crédito con el bien o derecho gravado.

Este es un aspecto de significativo interés y relacionado con las valuaciones de los intangibles para el acreedor, pues en este orden, luego de subastado o adquirido el derecho, no es dable ninguna otra exigencia como parte del cumplimiento de la obligación debida.

Lo señalado tiene una relación directa con la función de las garantías -y específicamente, en el caso de la prenda, con el ius distrahendi-, en el entendido de satisfacer el cumplimiento de la obligación con el valor del bien, en este caso, el intangible.

1) Modificación a la Ley 7 "Ley de Procedimiento Civil, Administrativo, Laboral y Económico”, de 19 de agosto de 1977.

Como se había esbozado previamente, en esta norma se modifica el precepto 3 del artículo 486 de la Ley 7, en el sentido de adicionar un apartado, que será el 7), con el texto siguiente: "Las garantías derivadas de los contratos".

m) Artículo 4. Las organizaciones superiores de dirección empresarial, las empresas estatales, las sociedades mercantiles de capital totalmente cubano y las modalidades de inversión extranjera pueden prendar sus bienes y derechos, previa autorización del Consejo de Ministros.

Ya en esta regulación se coarta la decisión de prenda de derechos al sector empresarial, en tanto se exige la autorización del Consejo de Ministros y limita la voluntad de las partes.

Es así que es precisamente el Comité Ejecutivo del Consejo de Ministros el que otorga la autorización para la constitución de inversiones extranjeras, no así para el resto de las organizaciones y entidades que se enuncian. Al parecer, en este caso se pretende unificar en un solo ente el control y autorización de este tipo de garantías. No obstante, aquellas otras personas que pueden intervenir en este tipo de operaciones, como por ejemplo las cooperativas no agropecuarias, no precisarían este tipo de autorización, existiendo obviamente un tratamiento diferente para la misma institución jurídica.

En el caso de Cuba, los principales o más valiosos derechos de propiedad industrial, ya sea en las marcas como en las patentes, están en poder del sistema empresarial en algunas de esas modalidades ya descritas.

Es llamativo el hecho de que se imponga tal obligación incluso a todas las modalidades de inversión extranjera, pues debe tenerse 
en cuenta que existen modalidades 100 por ciento extranjeras que tienen derechos de propiedad intelectual totalmente propios, sin intervención nacional, y pueden entenderse limitadas las facultades dispositivas.

La ratio en este caso podría estar, a juicio de esta autora, a través del Comité Ejecutivo del Consejo de Ministros, y cualquier modificación de sus documentos o del objeto de autorización debe contar con la autorización correspondiente de esta entidad, tal y como se regula en el artículo 20 del Reglamento a la Inversión Extranjera. Así, es posible que se haya realizado una interpretación extensiva de su intervención en estos supuestos.

La norma otorga fuerza ejecutiva a las garantías derivadas de los contratos mediante la adición de un apartado al artículo 486 de la Ley de Procedimiento Civil, Administrativo, Laboral y Económico, por lo que se puede instar directamente al Tribunal solicitando la ejecución de este título.

\section{Conclusiones}

Luego de este acercamiento a la posibilidad de conveniar garantías crediticias basadas en derechos de propiedad intelectual en Cuba, específicamente en modalidades de inversión extranjera, se puede arribar a las siguientes conclusiones preliminares.

El Decreto Ley 14 de 2020 es un avance en la estructuración de fuentes de financiamiento y garantías en las operaciones comerciales en la República de Cuba, pues incluye derechos, acciones y bienes intangibles como objeto de derecho de prenda.

Esta norma es de aplicación a personas naturales y jurídicas, cubanas y extranjeras específicamente para el ejercicio de sus actividades comerciales.

En el caso de las personas jurídicas, necesitan para que les sea concedida la prenda obtener la autorización del Consejo de Ministros. No se distingue la nacionalidad del titular de los derechos de propiedad intelectual en cuanto a esta exigencia.

Una correcta aplicación de la norma de referencia puede traer beneficios a las inversiones extranjeras y dotar de frescura a las ya tradicionales y envejecidas garantías operacionales. A pesar de sus 
beneficios, para una implementación efectiva deben establecerse reglamentaciones que llenen los vacíos legales existentes.

Corresponde ahora instar, fomentar y elevar esta figura por parte de los operadores del derecho en Cuba, hasta ahora de escasa o nula aplicación.

\section{Bibliografía}

Campos, M., Gutiérrez, C. I. y Saracho Martínez, A. (s.f.). La propiedad intelectual como motor de La competitividad en México. http://www.eseade.edu.ar/ files/ciima/investigacion/Propiedad\%20intelectual.pdf.

Díaz, A. (febrero de 2008). América Latina y el Caribe: La propiedad intelectual después de los tratados de libre comercio. Comisión Económica para América Latina y el Caribe (CEPAL)

Esquivel, G. y Larraín, F. (junio de 2001). ¿Cómo Atraer Inversión Extranjera Directa? Proyecto Andino de la Universidad de Harvard y la Corporación Andina de Fomento (CAF). https://www.academia.edu/39866999/C\%C3\%B3mo_Atraer_Inversi\%C3\%B3n_Extranjera_Directa.

Guadagno, F. y Wunsch-Vincent, S. (2020). Introduction to the GII 2020 theme. Who will finance innovation? En The Global Innovation Index 2020 (pp. 67-73). https://www.wipo.int/edocs/pubdocs/en/wipo_pub_gii_2020-chapter3.pdf.

Longcroft, L. (septiembre de 2008). Introducción a la financiación basada en la propiedad intelectual. Revista de la OMPI. https://www.wipo.int/wipo_magazine/es/2008/05/article_0001.html.

Martínez Piva, J. M. (Coord.). (2008). Generación y protección del conocimiento: propiedad intelectual, innovación y desarrollo económico. https://www.cepal.org/ es/publicaciones/2873-generacion-proteccion-conocimiento-propiedad-intelectual-innovacion-desarrollo.

Moreno Ávila, L. F. y Patiño Gutiérrez, G. A. (2020). Estructuración de garantías reales no tradicionales, basadas en la valoración de marcas para empresas del sector farmacéutico con fines de acceso a financiación (Tesis de Maestría en Administración Financiera, Universidad EAFIT). https://repository.eafit.edu.co/handle/10784/26717? locale-attribute=es.

Moreno Cruz, M. y Vázquez D’Alvaré, D. (2017). Propiedad intelectual e inversión extranjera. En Mesa Tejeda, N. T., Prieto Valdéz, M., Fernández Martínez, M., Moreno Cruz, M., Vázquez de Alvaré, D., Suárez González, A., Pérez Inclán, C. A., Cobo Roura, N., Mendoza Díaz, J. y Solís, C. J. (2017). La inversión extranjera en Cuba. Una visión desde el derecho. Editorial de Ciencias Sociales. 
Pons, W. C. (2019). Los activos intangibles como garantías mercantiles. Casos prácticos (Ponencia). Evento Internacional de la Oficina Cubana de la Propiedad Industrial OCPI. Propiedad Industrial y Transferencia de Tecnología.

Salas Couce, C. (2007). La inversión extranjera directa en Cuba. Situación actual y propuesta de política. Análisis Económico, XXII(51), 123-140.

\section{Legislación citada}

Acuerdo sobre los Aspectos de los derechos de Propiedad Intelectual relacionados con el Comercio, Anexo 1C del Tratado de Marrakech que establece la organización Mundial del Comercio, 1994.

Constitución de la República de Cuba.

Decreto 325/2014.

Decreto 342/2018.

Decreto Ley 203/1999.

Decreto Ley 241/2006.

Decreto Ley 290/2011.

Ley 7/1977.

Ley $14 / 1977$.

Ley 59/1987.

Resolución 31/2018.

Resolución 63/2000. 
